\title{
Using micronized progesterone for treatment of premenopausal age women suffering from severe premenstrual syndrome
}

\author{
Olha Horbatiuk ${ }^{1 \star}$, Alla Binkovska ${ }^{1}$, Olena Herych ${ }^{1}$, Andriy Ropotan ${ }^{2}$, \\ NATALIA ZhYLKO ${ }^{2}$, IRYNA MANDZIY ${ }^{2}$, IRYNA BULEZA ${ }^{2}$ \\ ${ }^{1}$ Department of Obstetrics and Gynecology, Faculty of Postgraduate Education, National Pirogov Memorial Medical University, 29000 \\ Vodoprovidna 8/1, Khmelnytsky, Ukraine \\ ${ }^{2}$ City Prenatal Center, Khmelnytsky, Ukraine

\section{ARTICLE INFO} \\ Received 13 June 2017 \\ Accepted 10 October 2017

\section{Keywords:} \\ PMS, \\ treatment, \\ per menopause, \\ micronized progesterone.

\begin{abstract}
In this study, we carried out the clinical and laboratory research of severe PMS (premenstrual syndrome) treatment in premenopausal age women. Herein, 37 women were examined and observed before the beginning of treatment and three months after it. Medication containing micronized progesterone was used for treatment (sublingually, $100 \mathrm{mg}$ from 11 to 25 days of menstrual cycle). After three months of micronized progesterone treatment, $86.5 \%$ of all women-participants of the study were observed to have full regression of clinical symptoms, while $13.5 \%$ of all patients were observed to have decrease in clinical symptoms of severe PMS. Moreover, hormonal research results revealed significant (1.3 times) decrease in LH (Luteinizing hormone) level and (1.3 times) increase in progesterone level after three months of treatment $(\mathrm{p}<0.05)$. The high bio-accessibility of the medication and its natural structure made it possible to decrease the dose and avoid risks of hepatotoxicity.
\end{abstract}

\section{INTRODUCTION}

Premenstrual syndrome (PMS) is a complex of symptoms that occur 2-10 days before menstruation and disappear at the beginning of menstruation bleeding. PMS is usually characterized by psycho-emotional, vascular and endocrine exchange disorders $[2,4,8,10]$. The interest in this issue has grown significantly for the last years due to the increased frequency of the disease and the intensification of its clinical symptoms. The occurrence of PMS depends on the age of women, and, in number, fluctuates from $20 \%$ of all women who are in their thirties, to $55 \%-90 \%$ of all women who are in their forties and older [4,10]. Emotionally labile women, women suffering from body weight deficiency and those, having intellectual overloads are predisposed to more frequent PMS $[4,5,8]$.

The etiopathogenic mechanisms of PMS jave not been fully studied. It is known, however, that progesterone deficiency in the second phase of the menstrual cycle is an important moment in the pathogenic chain of PMS occurrence. This brings about relative hyper-estrogenemia that leads to sodium and water retention and development of the edema syndrome in different organs and tissues, as well

\footnotetext{
* Corresponding author

e-mail: shymanskaolga09@gmail.com
}

as sensations of pain, especially in the mammary glands $[4,8,10]$. Estrogens dominance in the second phase of the menstrual cycle brings about many proliferative processes in the mammary gland which are accompanied by sensations of pain, tension and edema $[1,4]$.

The premenstrual syndrome in the premenopausal period has several notable peculiarities. Firstly, the premenopausal period is characterized by an imbalance in the rhythm of estradiol, progesterone, inhibin, aktivin secretions, as well as in the gonadotropin-releasing hormones. Secondly, ahormonal deficiency in the ovaries is developed as the result of the progressive exhaustion of the follicular apparatus. Thirdly, a shortage of follicle-stimulating hormones (FSH) and luteinizing hormones (LH) phases and an increase in the number of anovular cycles can be observed [1,2,4,8,9].

Several diverse therapeutic means for complex PMS treatment in the premenopausal period exist. These include gestagens administration in the second phase of the menstrual cycle, combined oral contraceptives, inhibitors of prostaglandins (non-steroid resolvents), selective inhibitors of reversal serotonin seizure, vitamin treatment, metabolic medicine, immune system correctors and adaptors, as well as vasoactive medicine etc. $[1,5,7,9,10]$. 
Taking into account the wide range of medicine applied in the treatment of PMS, and the polypragmasia trend typical of modern medicine, the main task of our research is by means of utilizing a single effective medication, to minimise the PMS symptoms for women at the premenopausal age by decreasing the number of side effects and complications induced by prescribed medications.

In order to complete the given task, we have chosen a medication which contains micronized progesterone. This medicament is identical to the one organically synthesized. Accordingly, the metabolites of micronized progesterone are identical to the metabolites of natural progesterone and have no toxic influence on the organism (unlike their synthetic analogues). The micronized form of progesterone provides high penetration through the mucous membranes and high bio-accessibility, as well as interaction only with the progesterone receptors. In addition, there are no estrogen, androgen and glucocorticoid effects. In our study, a sublingual administration of the chosen drug was applied because doing so made it possible to avoid initial liver interaction, as the result of its maximum absorption in the mouth cavity. Hence, medicine bio-accessibility is increased which makes it possible to decrease the dose and avoid risks of hepatotoxicity [6]. Thus, in prescribing micronized progesterone, we restore the natural hormonal balance. Of note, in the Ukraine market, micronized progesterone is the only form of progesterone available.

\section{AIM}

The evaluation of severe PMS treatment efficiency by means of micronized progesterone for premenopausal age women who have preserved menstrual cycle.

\section{MATERIALS AND METHODS}

The study group consisted of 37 premenopausal age women with preserved menstrual cycles who suffered from severe premenstrual syndrome and were within either the compensated, sub-compensated and de-compensated stage (the main group). This group received a micronized progesterone treatment (oral) dose of $100 \mathrm{mg}$ per day (as recommended for normal secretory transformation of the endometrium).

The tablets were taken sublingually from the 11th to 25 th days of the menstrual cycle (note: this medicine is usually prescribed for administration from the 14th to the 25th days of the menstrual cycle). Such treatment duration was chosen in order to model a full-value luteinizing hormone phase (the longest in the menstrual cycle, lasting 14 days). The level and stage of PMS severity were evaluated by means of summarizing the symptoms, their duration and expression $[2,4,10]$. Women who had hypertrophy of endometrium or endometrial polypus (according to ultrasound examination) were not included in the main group. The participants agreed in writing to be part of the study group.

The control group consisted of 32 premenopausal age women who had preserved menstrual cycle and who did not suffer from PMS.
In the study, basal temperature and stages of pituitary and ovary hormones (LH, FSH, prolactin, estradiol, progesterone, and testosterone total) for both women of the main and control groups (before the beginning of treatment and three months after it) were analyzed. Basal temperature was measured during three menstrual cycles (m.c.) according to all methodical requirements.

The level of hormones in the blood plasma was measured by radio-immune methods utilizing 'Immunotech' test systems sets (Czech Republic). The hormones analyzed include: LH, FSH, LH / FSH, PRL (prolactin), estradiol, progesterone and total testosterone. As fluctuation in prolactin levels often lead to various disorders of the menstrual cycle, this was drawn together with the other hormones. The hormonal research was carried out in the early follicular phase (2-4 days of a menstrual cycle).

Statistical data were processed by means of Excel adapted for medical and biological research. Willcockson's non-parametric criteria for even samples were used for comparison of quantitative data before and after the treatment period. When difference was found, paired comparisons of groups by means of Mann-Whitney criteria were employed. Differences were recognized reliable when the level of significance was $\mathrm{P}<0.05$ [3].

\section{RESULTS AND DISCUSSIONS}

All the women of the main and control groups were at premenopausal age (45-50 years old). According to the severity of PMS, the women of the main group were categorized in the following way: 19 (43.2\% of all) women were registered as having severe PMS and being in the compensated stage of the disease; 11 (29.7\% of all) women were registered as having severe PMS and being in the subcompensated stage of the disease; 7 (18.9\% of all) women were registered as having severe PMS and being in the decompensated stage of the disease. All the severe forms of the disease were typical of women whose work was connected with hard intellectual loads (teachers, bankers, office workers, accountants, doctors etc). Women whose PMS were not reported as severe, were not included in the research. According to the anamnesis of the women of the main group, the duration of the disease is synchronized with PMS severity (Tab. 1). The longer PMS lasts, the more severe it is.

Table 1. Duration of the disease for women who suffer from PMS

\begin{tabular}{|c|c|c|c|}
\hline \multirow{2}{*}{$\begin{array}{c}\text { Duration of the } \\
\text { disease, years }\end{array}$} & \multicolumn{3}{|c|}{ Main group of women $(n=37)$} \\
\cline { 2 - 4 } & $\begin{array}{c}\text { Severe PMS, } \\
\text { compensated stage } \\
(n=19)\end{array}$ & $\begin{array}{c}\text { Severe PMS, sub- } \\
\text { compensated stage } \\
(n=11)\end{array}$ & $\begin{array}{c}\text { Severe PMS de-de- } \\
\text { compensated stage } \\
(n=7)\end{array}$ \\
\hline$<1$ & $11(29.7 \%)$ & $3(8.1 \%)$ & $0(0 \%)$ \\
\hline $1-5$ & $8(21.6 \%)$ & $7(18.9 \%)$ & $3(8.2 \%)$ \\
\hline $6-10$ & $0(0 \%)$ & $1(2.7 \%)$ & $4(10.8 \%)$ \\
\hline
\end{tabular}

In their back history, we noted that in their reproductive period, all 37 (100\%) women had significant fertility dysfunctions (limited lactation, abortions, miscarriages, ovary cysts). However, only 9/37 women (28.1\%) had infertility and extra-uterine pregnancy in their anamnesis.

With regard to basal temperature, 111 menstrual cycles of the main group women and 96 menstrual cycles of the 
control group women were analyzed (Tab. 2). Herein, we found that most premenopausal age women of both groups had a mono-phase anovular menstrual cycles. Still, the women who suffer from PMS were observed to have an increase in the number of menstrual cycles, with second phase shortening $(15.3 \%$ against $11.3 \%$ in the control group), and a decrease in frequency of the two-phase ovular cycles (6.3\% against $16.7 \%$ in the control group).

Table 2. Basal temperature of women who suffer from PMS before treatment analysis

\begin{tabular}{|c|c|c|c|}
\hline $\begin{array}{c}\text { Menstrual } \\
\text { cycles number }\end{array}$ & $\begin{array}{c}\text { Two-phase ovular } \\
\text { menstrual cycle, } \mathrm{n}\end{array}$ & $\begin{array}{c}\text { Mono-phase } \\
\text { anovular } \\
\text { menstrual cycle, } \mathrm{n}\end{array}$ & $\begin{array}{c}\text { Two-phase menstrual } \\
\text { cycle, with the second } \\
\text { phase shortening, } n\end{array}$ \\
\hline $\begin{array}{c}\text { Main group } \\
(\mathrm{n}=111)\end{array}$ & $7(6.35 \%)$ & $87(78.4 \%)$ & $17(15.35 \%)$ \\
\hline $\begin{array}{c}\text { Control group } \\
(\mathrm{n}=96)\end{array}$ & $16(16.7 \%)$ & $69(71.8 \%)$ & $11(11.5 \%)$ \\
\hline
\end{tabular}

The increase in the frequency of two-phase cycles allied with the second phase shortening indicates luteinizing hormones phase deficiency (verified by hormonal research) and a pathogenesis grounding for micronized progesterone prescription so as to correct the given condition.

What is more, all the premenopausal aged women displayed the typically premenopausal increase in the concentration of gonadotropin hormones and the decrease in the concentration of ovary hormones. The women of the main group (Tab. 3) also had significantly higher levels of pituitary hormones (FSH, LH) and significantly lower levels of ovary hormones (progesterone) when compared with the control group.

Tab. 3: Hormonal data before treatment for premenopausal aged women who suffer from PMS $(\mathrm{M} \pm \mathrm{m})^{*}$

\begin{tabular}{|l|c|c|c|c|}
\hline \multicolumn{1}{|c|}{ Hormone } & $\begin{array}{c}\text { Measurement } \\
\text { unit }\end{array}$ & $\begin{array}{c}\text { Main group } \\
(\mathrm{n}=37)\end{array}$ & $\begin{array}{c}\text { Control group } \\
(\mathrm{n}=32)\end{array}$ & $\mathrm{p}$ \\
\hline $\mathrm{LH}$ & $\mathrm{IU} / \mathrm{L}$ & $34.82 \pm 3.58$ & $13.71 \pm 1.09$ & $<0.05$ \\
\hline $\mathrm{FSH}$ & $\mathrm{IU} / \mathrm{L}$ & $16.2 \pm 1.55$ & $10.61 \pm 1.17$ & $<0.05$ \\
\hline $\mathrm{LH} / \mathrm{FSH}$ & ratio & $2.13 \pm 0.51$ & $1.29 \pm 0.10$ & $<0.05$ \\
\hline $\mathrm{PRL}$ & $\mathrm{mIU} / \mathrm{L}$ & $268.21 \pm 15.17$ & $233.70 \pm 27.16$ & $>0.05$ \\
\hline Estradiol & $\mathrm{ng} / \mathrm{L}$ & $105.82 \pm 5.85$ & $114.08 \pm 6.70$ & $>0,05$ \\
\hline Progesterone & $\mathrm{ng} / \mathrm{mL}$ & $0,34 \pm 0.03$ & $0,45 \pm 0.03$ & $<0.05$ \\
\hline $\begin{array}{l}\text { Testosterone } \\
\text { Total }\end{array}$ & $\mathrm{nmol} / \mathrm{L}$ & $1,86 \pm 0.18$ & $1,67 \pm 0.21$ & $>0.05$ \\
\hline
\end{tabular}

* $\mathrm{M} \pm \mathrm{m}$ - mean and standard deviation

Thus, LH level was significantly (2.5 times) higher when compared to the control group; FSH level was 1.5 times higher; and the ratio of LH/FSH increased 1.5 times $(p<0.05)$. Furthermore, we observed a 1.5 times increase in prolactin when compared with the control group ( $p>0.05)$. In addition, estradiol level was 1.08 times lower $(\mathrm{p}>0.05)$, and progesterone level was significantly lower - by 1.32 times $(p<0.05)$. The total testosterone concentration, however, was the same as that of the control group.

A control examination of the women who had severe PMS was carried out three months after their treatment began. In this, it was seen that the condition of five women out of seven who suffered from severe PMS and were within the de-compensated stage (13.5\%) had improved; their psycho-pathologic and neurologic symptoms and mastalgia trouble had diminished. Their main complaints, however, included nausea and flatulence (the residual effects of gastrointestinal syndrome). Of note: two (5.4\%) women within the de-compensated stage of severe PMS, nine (24.3\%) women within the sub-compensated stage of severe PMS and 17 (45.9\%) patients within the compensated stage of severe PMS had no complaints at all. Still, two (5.4\%) women within the sub-compensated stage of severe PMS and two (5.4\%) patients within the compensated stage of severe PMS had no complaint regarding PMS, but complained of having nausea, headache, dizziness and dryness in their mouth cavity (the possible side effects of the medicine). Despite prolonged use of progesterone (from 11 to 25 days of their menstrual cycle), disorders of duration of menstrual cycle were not detected.

Table. 4 Hormonal data for premenopausal age women who suffered severe PMS - after three months treatment, $(\mathrm{M} \pm \mathrm{m})$

\begin{tabular}{|l|c|c|c|c|}
\hline \multicolumn{1}{|c|}{ Hormone } & Unit & $\begin{array}{c}\text { Main group } \\
(\mathrm{n}=37)\end{array}$ & $\begin{array}{c}\text { Control group } \\
(\mathrm{n}=32)\end{array}$ & $\mathrm{p}$ \\
\hline $\mathrm{LH}$ & $\mathrm{IU} / \mathrm{L}$ & $26.32 \pm 4.11$ & $13.92 \pm 2.25$ & $<0.05$ \\
\hline $\mathrm{FSH}$ & $\mathrm{IU} / \mathrm{L}$ & $15.29 \pm 1.87$ & $11.12 \pm 1.30$ & $<0.05$ \\
\hline $\mathrm{LH} / \mathrm{FSH}$ & $\mathrm{ratio}$ & $1.72 \pm 0.23$ & $1.25 \pm 0.21$ & $<0.05$ \\
\hline $\mathrm{PRL}$ & $\mathrm{mIU} / \mathrm{L}$ & $259.34 \pm 23.87$ & $238.63 \pm 21.01$ & $>0.05$ \\
\hline Estradiol & $\mathrm{ng} / \mathrm{L}$ & $107.53 \pm 6.36$ & $112.48 \pm 7.15$ & $>0.05$ \\
\hline Progesterone & $\mathrm{ng} / \mathrm{mL}$ & $0.43 \pm 0.09$ & $0.44 \pm 0.28$ & $>0.05$ \\
\hline $\begin{array}{l}\text { Testosterone } \\
\text { Total }\end{array}$ & $\mathrm{nmol} / \mathrm{L}$ & $1.81 \pm 0.22$ & $1.72 \pm 0.19$ & $>0.05$ \\
\hline
\end{tabular}

Post-treatment, the women of the main group were observed to have significant LH decrease $(\mathrm{p}<0.05$; from $34.82 \pm 3.58$ to $26.32 \pm 4.11$ ), a slight (non-significant) FSH
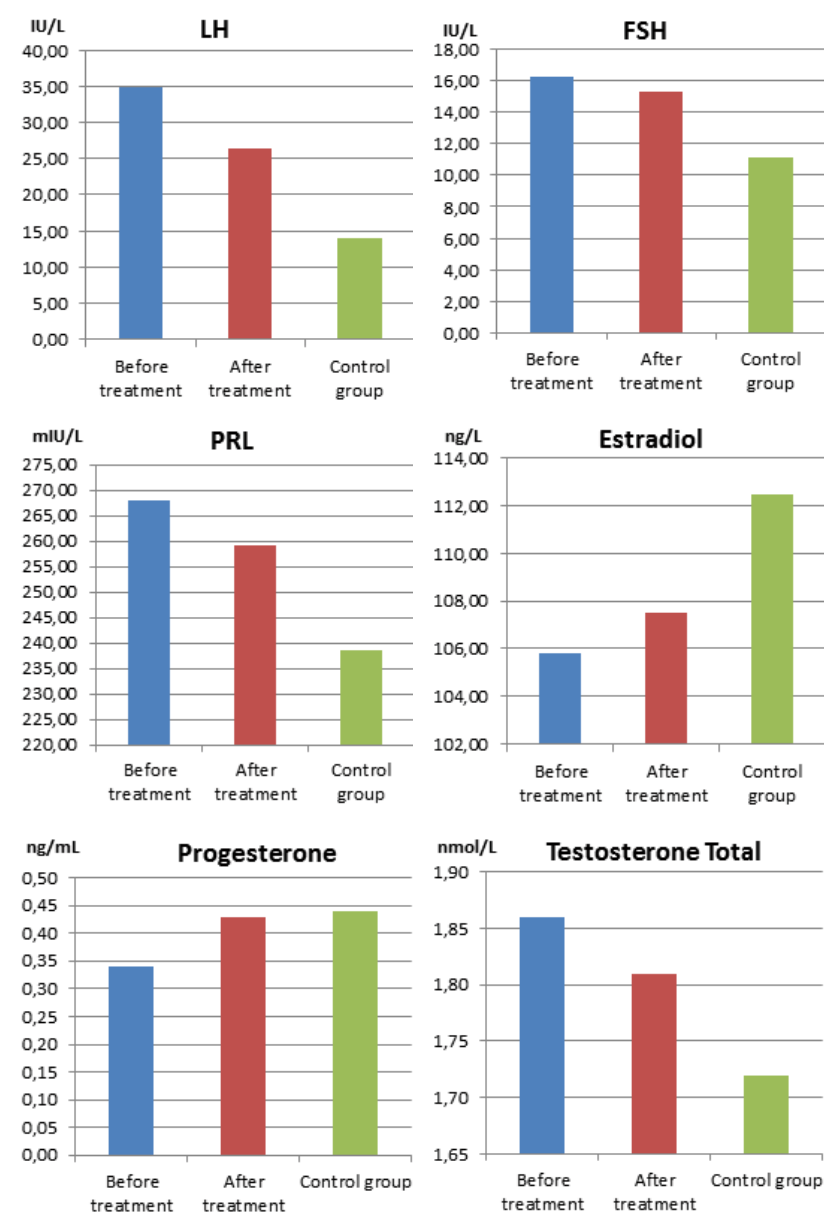

Figure 1. Dynamics of changes in hormones pre- and posttreatment 
decrease $(\mathrm{p}>0.05)$, as well as changes in ratio of $\mathrm{LH} / \mathrm{FSH}$, prolactin and general testosterone, in addition to slight estradiol changes (not significant). What must be underlined is that progesterone level had increased statistically significantly $(\mathrm{p}<0.05)$, from $0.34 \pm 0.03$ to $0.43 \pm 0.09$ - and reached the control level (Fig.1).

\section{CONCLUSIONS}

According to our research results, $86.5 \%$ of all women of the main group were observed to have had full regression of severe PMS clinical effects, while $13.5 \%$ of all women suffering from severe PMS and who were within the decompensated stage were observed to have a decrease in PMS symptoms. Furthermore, the undertaken hormonal diagnostics demonstrated significant (1.3 times) LH level decrease and significant (1.3 times) progesterone increase three months after severe PMS treatment by means of administration of micronized progesterone $(\mathrm{p}<0.05)$. We also observed a non-significant, slight FSH level decrease, and (non-significant) changes in the ratio of LH/FSH, prolactin, total testosterone and estradiol. Our study demonstrates that the high bio-accessibility of the medication and its natural structure made it possible to decrease the dose and avoid risks of hepatotoxicity. It can be said, therefore, that the given research has verified the expedience of micronized progesterone application for severe PMS treatment of any stage.

\section{REFERENCES}

1. Hryhorenko, A.P., Horbatiuk, O.H., Shatkovska, A.S.: Menstrual cycle and its regulation. Meditsinskiye aspekty zdorovya zhenshchin, $17,4,2012$.

2. Hryhorenko, A.P., et al. Correction of premenstrual syndrome in perimenopausal women. Meditsinskiye aspekty zdorovya zhenshchin, 51, 3, 2017.

3. Kochetov, A.G. et al., (2012). Methods of statistical medical data processing: methodical guideline for postgraduate students. Moscow: RKNPK; p. 42.

4. Manuhin, I.B. Tumilovich, L.G. Gevorkian, M.A. (2014). Gynecological endocrinology. Clinical lecture: guideline. Moscow: Geotar-Media; p. 267.

5. Nappi, R.E., et al. Luteal phase dysphoric disorder and premenstrual syndrome. Ital. J. Psych. Behav. Scien., 27, 28, 2009.

6. Opryshko, V.I. Nosivets D.S.: The originality of the forms of micronized progesterone. Z turbotoyu pro zhinku, 12, 8, 2016.

7. Saidova, R.A., Aleksanian, S.G., Tropynina, E,V.: Contemporary principles of the hormonal correction of menstrual disorders in perimenopausal period. Voprosy gynekologiyi, akusherstva i perinatologiyi, 46, 4, 2008.

8. Studd, J. Spotlight on severe premenstrual syndrome and bipolar disorder: a frequent tragic confusion. Climacteric, 602, 14, 2011.

9. Tatarchuk, T.F. et al., (2000). Principles and methods of correction of the hormonal disorders in peri - and post-menopause: methodical guideline. Kiev; p. 25.

10. Vichlayeva, Y.M., editor (2006). Guideline for endocrinological gynecology. Moscow: MIA; p. 784. 